\title{
Assimilation Capacity Changes of Gharehsou River, East of Ardabil Province, Iran using Qual2kw Model
}

\author{
1*YASER, H; ${ }^{2}$ PEGAH, H \\ ${ }^{1 *}$ Moghan College of Agriculture and Natural resources - University of Mohaghegh Ardabili - Ardabil - Iran \\ ${ }^{2}$ Natural Resources and Environmental Engineering, Malayer University, Malayer, Iran \\ *Corresponding author Email: y_hoseini@uma.ac.ir.Tel: +989163069199
}

\begin{abstract}
In this study, the assimilative capacity changes of the Gharehsou River has been studied. Gharehsou River, in the East of Ardabil province of Iran in its flow path, is the entrance and discharge domestic sewage, industrial wastewater and agricultural drainage and for determining of assimilative capacity of this river, first, the calibrated model of Qual2kw simulated parameters change of $\mathrm{NO}_{3}, \mathrm{BOD}, \mathrm{DO}, \mathrm{pH}$ and temperature for two months of January and July, and then it was compared with observational data in Aladizgeh, Samian, Anzob and ArbabKandi stations. The best model simulation for $\mathrm{pH}$ parameter was obtained and in the next ranks, the parameters were, respectively $\mathrm{DO}, \mathrm{BOD}, \mathrm{NO}_{3}$, and Temperature. The results show low assimilative of parameters in Gharehsou River and the severe impact of non-point sources in it. Results showed that measured and modeled values have a good agreement with each other and the simulation in these parameters has been done well.
\end{abstract}

\section{DOI: $\underline{\text { https://dx.doi.org/10.4314/jasem.v22i7.14 }}$}

Copyright: Copyright $\odot 2018$ Yaser and Pegah. This is an open access article distributed under the Creative Commons Attribution License (CCL), which permits unrestricted use, distribution, and reproduction in any medium, provided the original work is properly cited.

Dates: Received: 05 January 2018; Revised: 20 April: 2018; Accepted: 17 July 2018

Keywords: Gharehsou River, assimilative, physical and chemical parameters, Qual2kw

Water pollutants include materials that change the physical, chemical and biological properties of water, and mainly, these materials caused by human activities and they are classified into three main groups of industrial, urban and agricultural pollution sources (Erfanmanesh and Afioni, 2006). Gharehsou River originates from the Talysh Mountains (Baghru) in the East of Ardabil province of Iran, and on its way, while crossing the plains of Ardabil, collects water in this part, including Balikhlychay and eventually, it discharges to the river Aras at the Aslanduz. Gharehsou River (Mohammadi et al., 2015). "Assimilative capacity" is called a set of interaction that occurs naturally in a water source and as a result, the level of water pollution decreased during natural processes and water quality increases to the optimum standard. Factors that contribute to this phenomenon include the rate of transfer, penetration and distribution, sedimentation and pollutant decomposition (Hoseini et al., 2007). Qualitative modeling of the rivers is one of the most important and low-cost tools in checking problems and solutions, in order to improve the quality of the river. In this study, one-dimensional model of Qual2kw is used. This model considers water quality variable in a state of steady flow and non-uniform. Qual2kw will model the algae production and dissolved oxygen with the effect of water substrate and carbon demand in the flows (Asheghmala et al., 2014). Oliveir et al. (2011) evaluated the water quality application of the Qual $2 \mathrm{kw}$ model for small basin rivers, and the response of Sertima River to different loadings of nitrogen and phosphorus with the help of this model. The simulation results showed that for an actual reduction of pollution resulting from the loading of nitrogen and phosphorus, respectively 5 and 10 periods are necessary so that the class of this river changes from eutrophic to metopic. Cristea and Burges (2010) used Qual2kw model to simulate the minimum and maximum water temperature in three rivers of America they proposed to increase vegetation along the river in order to protect aquatic life. Kannel et al. (2011) simulated dissolved oxygen in a river in America, with six different models, namely; (SIMCAT, WASP7, TOMCAT, Qual2eu, QUASAR, and Qual2kw). The findings show that the outputs of the two models, SIMCAT TOMCAT are very simplistic, but helpful in order to review the point sources. Two models of QUASAR, WASP7 are much better than the Qual2eu model due to considering the mortality effect of algae. In Arrudacamargo et al. (2010) research, the calculations of simulation water quality were calibrated and validated with Qual $2 \mathrm{kw}$ model and the assimilative ability of Karstic small 
drainage was evaluated in the emission non-point sources, the results showed that the lowest dissolved oxygen during periods was 4.7 and $5.4 \mathrm{mg} / \mathrm{L}$ that are above the standard minimum set by the Environmental Protection Agency of America to protect aquatic communities. Asheghmala et al. (2014) with the use of Qual2kw model carried out the simulation of two scenarios on the Gheshlagh River in Kurdistan. The first scenario of DO and BOD concentration was 2 and $30 \mathrm{mg} / \mathrm{L}$ based on the current standard limits for wastewater discharge, and the second scenario was considered based on the assimilative capacity of the river to the minimum amount of DO $(5 \mathrm{mg} / \mathrm{L})$, limit 50 $\mathrm{mg} / \mathrm{L}$ for parameter BOD and it was stimulated by the model. Economic comparisons of these two scenarios showed the second scenario superiority with the economic cost difference of 10 billion rails. In this study, first, the changes in water quality parameters were stimulated with the help of QUAL2KW model and It was done according the input pollutant load volume, for two months of July (Water shortage) and January, and finally, assimilative of the river was analyzed according to the measured point values in the location of the stations.

\section{MATERIALS AND METHODS}

The study area: This research has examined the water quality of the Gharehsou River from Aladizgeh station with the latitude of $38^{\circ} 17^{\prime}$ Northern and longitude $48^{\circ} 35^{\prime}$ Eastern and average height of 1347 meters above sea level to the Arbab Kandi station with the eastern longitude of $48^{\circ} 01^{\prime}$ and latitude of $38^{\circ} 29^{\prime}$ northern and the average height of 1116 meters above sea level in Ardabil Province of Iran. In fact, about $90.6 \mathrm{~km}$ from the length of the river was qualitatively assessed. Based on information obtained from preliminary studies and identifying the river and determining the water withdrawals place and sewage disposal into the Gharehsou River, in this study, the data from four hydrometric stations were used that information was collected from the Organization Department of the Environment and Water Resources in Ardabil Province. This information includes values of physical and chemical parameters DO, BOD, $\mathrm{NO}_{3}$, $\mathrm{pH}$, flow and temperature in July and January 2015. Stations located on the River are Aladizgeh Station, Samian (in July), Anzob, and Arbab Kandi station. It should be noted that since in January 2015, Figure 1 shows the location of the study area and stations on the Gharehsou River.

Pollutant sources in the model are point sources that its information about physical and chemical parameters was collected from the Environment Department of Ardabil province. Figure 2 shows the entering positions of these pollutant sources to the Gharehsou River.

The model simulation and validation: Given that, the river water quality is influenced by flow and temperature, to determine the critical month, with flow analysis of water shortage conditions, in the 20 statistical years, at selected stations, the month of July was selected as the water shortage month. Changes in the Gharehsou River water quality simulation were done by Qual2kw model in July and January and it was compared with the quality parameters measured in the same months. After entering the required input data, the model is applicable in a few minutes in two methods of FORTRAN and VBA. The results of both methods, in the end, were the same, but the speed of simulations in FORTRAN is a little more, that VBA format is used in this study. To assess the accuracy of simulation parameters with the observational values, the square correlation coefficient $\left(\mathrm{R}^{2}\right)$ and mean absolute error (MAE) were used (Mohammadi et al., 2015). In the simulation parameters, as the correlation coefficient is closer to one and the mean absolute error is closer to zero, the function of model has higher reliability. MAE value is calculated according to Equation (1).

$$
M A E=\frac{1}{N} \sum_{i=1}^{N}\left|Q_{i}-P_{i}\right| \quad 1
$$

$\mathrm{X}_{\mathrm{o}}$ : the observed values, $\mathrm{X}_{\mathrm{p}}$ : simulated values, $\mathrm{N}$ : number of samples

\section{RESULTS AND DISCUSSION}

Figures (3A) show the amount of dissolved oxygen (DO) predicted by the model, dissolved oxygen saturation and measured values in July and January respectively in Gharehsou River. The amount of dissolved oxygen in the rivers depends on several factors including water temperature, re-aeration rate, available organic load or input into the river. As seen in Figure 3A, the oxygen content, simulated by the Qual2kw model in the first station (Aladizgeh) is less than the measured values, but in the intermediate station (Samian) and terminal station (Arbab Kandi), the observational values are lower than predicted values of the model. It seems the flow of point resources at $38 \mathrm{~km}$ (waste of vegetable oil factory) is low and did not have much impact in the dissolved oxygen of the river in this distance. Such as the results of a survey by Mirzaee et al., (2012) that was conducted in the rivers of Babol Rood, DO curve is with roughly the same values. In general, the DO is close to saturation line, which indicates good exchange of oxygen with river water in this month. $\mathrm{R}^{2}$ and MAE for this parameter were calculated 0.51 and 1.1respectively Figure $3 \mathrm{~A}$ shows, the amount of 
dissolved oxygen in January, in the primary and intermediate station, was lower than the simulated values, it seems, freezing water of the river in this season, especially in the Sarab mountainous region of Gharehsou River reduces the air flow of water and thus, reduces the DO in the measured values, even lower than July. Values of DO, in the end station have a good agreement with the model results, although its amount is lower than the amount of July. $\mathrm{R}^{2}$ and MAE for this parameter were calculated 0.87 and 2.4 respectively. Figure $3 \mathrm{~B}$ shows biochemical oxygen demand changes (BODf) in July in a range of studies. BOD value is observational in the first station (Aladizgeh), greater than simulated values by models, which could be due to seepage of agricultural runoff in upstream. The graph shows, the values of this parameter decline with steep at $21-29 \mathrm{~km}$, so that the amount reaches from 8.87 to $5.9 \mathrm{mg} / \mathrm{L}$. However, in this area, sewage of industrial Park and vegetable oil Company enters into the river Gharehsou, and it seems, input channels, in this way, reduce BOD despite the point sources. The chart, in the following, to the last station, shows an increase in this parameter up to $11.2 \mathrm{mg} / \mathrm{L}$, that abundant farmlands from $30 \mathrm{~km}$ onwards and runoff caused by watering them, could be outlined as the reasons for this increase. The measured values in the Samian and Arbab Kandi stations, to some extent, are lower than model predictions, but show the increase trend in this parameter to the end of the path. $\mathrm{R}^{2}$ and MAE values, for this parameter, were calculated respectively, 0.57 and 1.87. Figure 3B shows the BODf rate of change in January. This parameter in this month had a significant increase compared to the month of July, due to increased runoff and organic substances from washing farms, particularly from $30 \mathrm{~km}$ to the downstream of Gharehsou River. So that the measured values in this interval had fluctuation of the 21.75 to 29.71. In January, same as July, in Aladizgeh station, observational BODf values were higher than the values predicted by the model. In the middle station (Anzob), the measured values have been close to the values predicted by the model, but in Arbab Kandi station, the measured values were lower than the simulated values. The discrepancy between laboratory results and model results may be due to differences in sampling time of the river water with a sampling of the pollutant. These results are consistent with the study of Mohammadi et al., (2015) in Gharehsou River. They also pointed out that, although the BOD parameters are within normal limits, but the value in the stations is relatively high and this represents the low assimilative capacity of the river. In general, the BOD values in January were higher than the values of these parameters in July. Mehrdadi et al., (2006) in evaluating the assimilative potential of Tajan River, by using Qual -2E model also have stated that, the BOD and chemical oxygen demand (COD) in the second half of each year are more than the first half of it. $\mathrm{R}^{2}$ and MAE for this graph are calculated, respectively, 0.93 and 9.7. Figure 3C shows changes the amount of nitrate $\left(\mathrm{NO}_{3}\right)$, in the course of the study in July. In midJuly, adding nitrogen fertilizer to the soil, in planted potato fields, which is one of the main products of Ardabil province, caused a significant increase in this parameter in the soil and river water. In the first station (Aladizgeh), measured values of $\mathrm{NO}_{3}$ are higher than the simulated values and at $53 \mathrm{~km}$ of the study range; there is a good agreement between measured values in Samian station and simulated values by model. However, at the last station (Arbab Kandi), closest to the fields and washing the chemical fertilizer in these lands greatly increased nitrate in the water of the river, which would be quite evident in the measurements and model results at these stations. The amount of nitrate in the downstream is more than upstream that is consistent with the results of Selong and Helfrich (2002). $\mathrm{R}^{2}$ and MAE, for this chart are, respectively 0.1 and 3.5. Figure $3 \mathrm{C}$ shows nitrate changes $\left(\mathrm{NO}_{3}\right)$ by model in January. Since the input drains flow, increases in the winter compared to the summer (Nowshadi and Hatamizadeh, 2010). Therefore, in the first station (Aladizgeh), the values are measured and the model values have significant differences. This process continues in the middle station (Anzob) and end station (Arbab Kandi), due to the effect of runoff. That can be caused by non-point input flows in the direction into the river, which is acceptable according to the months of rainfall and different drainage input gain. In addition, the amount of nitrate refining is related to the DE nitrification process that the process works faster in static environments (such as depth of field) and decomposes nitrate with the help of amine and oxide bacteria (Pelletire and Chapra, 2005). For this reason, the rivers have less power in nitrate decomposition, which has been seen in examining the assimilative of the nitrate parameter in the Sefid Rood River by Azimi et al., (2010) with the implementation of Qual2kw model. In general, in the range of study and according to the simulated chart, nitrate parameter shows decreasing trend up to $28 \mathrm{~km}$, then takes an increasing trend up to the end of the path. $\mathrm{R}^{2}$ and MAE for this chart are calculated, respectively 0.68 and 0.85 . Figure $3 \mathrm{D}$ shows the changes in the acidity or $\mathrm{pH}$, along the river, in July. To determine the $\mathrm{pH}$, balance equations model, neutral electrons and mass balance, in which the inorganic carbon is the determining factor, are used. As the chart suggests, measured and modeled values in the first station (Aladizgeh) have a good agreement with each other and the simulation in this parameter has been done well. In addition, the value of this parameter is reduced 
to reach 6.4 units in $35 \mathrm{~km}$, and then with the arrival of vegetable oil factory waste, it increases to $43 \mathrm{~km}$, and reaches the number 8.25 . Then, the water $\mathrm{pH}$ of Gharehsou River remains constant and from $70 \mathrm{~km}$ onwards, it reaches 7.6 with a gentle slope, in the terminal station. In general, the simulation for this parameter is good. The correlation coefficient $\left(\mathrm{R}^{2}\right)$ and mean absolute error (MAE), for this month are calculated, respectively, 0.13 and 0.5 . Figure $3 \mathrm{E}$ shows the $\mathrm{pH}$ changes in the Gharehsou River in January. According to model predictions, $\mathrm{pH}$ values start from 4.17 and reach to 3.99 in $21.3 \mathrm{~km}$ and then reach to 6.8 units with a high steep at $28.8 \mathrm{~km}$. The increasing trend of $\mathrm{pH}$ in January is quite evident in the curve and the observational data at the surveyed stations. This is despite the fact that, the measured values at the first station (Aladizgeh) and the end station (Arbab Kandi) are higher than the simulated curve by the model. Generally, the river water is generally alkaline, that is consistent with the results of Nowshadi and Hatamizadeh, (2010) in reviewing Kor River. The correlation coefficient $\left(\mathrm{R}^{2}\right)$ and mean absolute error (MAE), for this month are calculated, respectively, 0.73and 1.4. Figure 3E shows Karun River water temperature changes in the 13 ranges of study in July. The measured values of Gharehsou River water temperature at all stations except the Arbab Kandi station are higher than the values predicted by the model. In this chart, the $\mathrm{R}^{2}$ and MAE are calculated, respectively, 0.33 and 3.6. Figure $3 \mathrm{E}$ shows temperature changes, in January by the model. The water temperature significantly reduced naturally, in this month, so that the values of simulated curves show the numbers of 2.4 on the first station and 11.66 ${ }^{\circ} \mathrm{C}$ in the last station. However, the observational values, in all three stations (Aladizgeh, Anzob and Arbab Kandi) showed the water temperature higher than $12{ }^{\circ} \mathrm{C}$. In fact, there is no good agreement between the model results and the measured values in this month and the model did not stimulate this parameter well. During this month, in this chart, the $\mathrm{R}^{2}$ and MAE are calculated, respectively, 0.8 and 7.9.

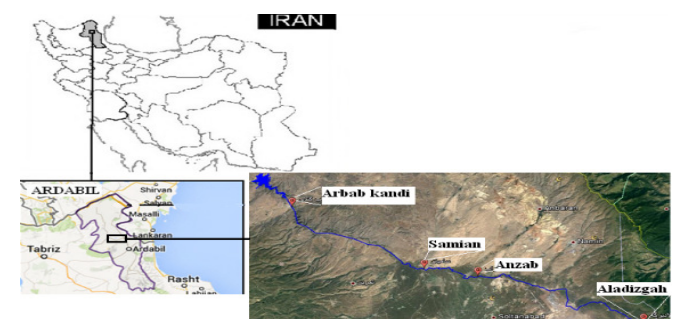

Fig 1: The location of selected stations on the Gharehsou River

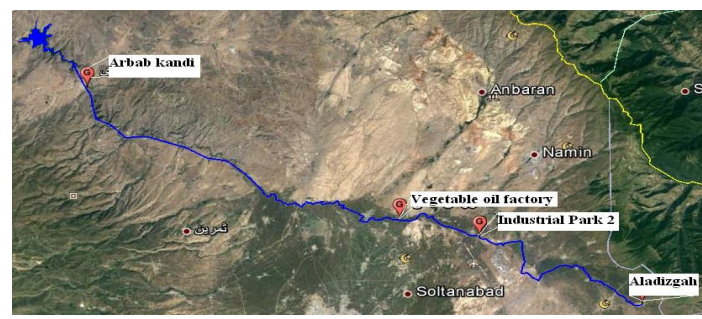

Fig 2: The position of point sources of pollutants entering the Gharehsou River
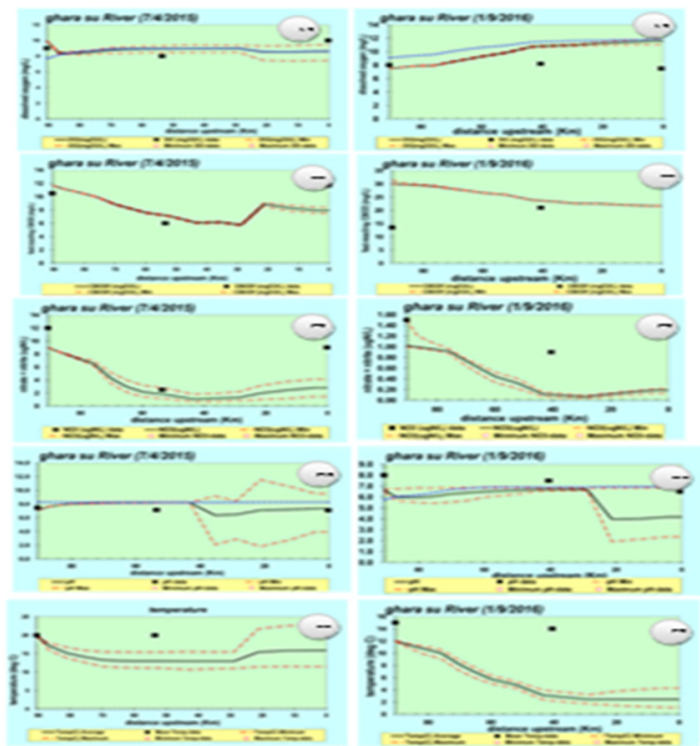

Fig 4: Measured and simulated $\mathrm{DO}, \mathrm{BOD}_{\mathrm{f}}, \mathrm{No}_{3} \mathrm{c}, \mathrm{pH}$, temperature, Changes in July and January

Conclusion: By simulating the variation charts, the parameters BODf, $\mathrm{DO}, \mathrm{NO}_{3}, \mathrm{pH}$ and temperature of the Gharehsou River, in the province of Ardabil, in July (water shortage) and January 2015 were identified by QUAL2kw model. Although, parameter values from upstream to downstream of the river is within the normal range, but, every two months, we observe an increase in the parameter values in the simulated charts and Gharehsou River has a few assimilative capacities to decompose input pollutants during its path. The most important pollutant of Gharehsou River is water-soluble substances, such as pesticides and fertilizers of the soil to the water of the river. In fact, in other words, the effects of non-point input sources, including many agricultural drainage, runoff from agricultural land irrigation around the Gharehsou River are more than the point sources such as industrial wastewater and rural sewage. Given the correlation coefficient $\mathrm{R}_{2}$ and the average absolute error (MAE), the best simulation for $\mathrm{pH}$ and then respectively, for temperature, $\mathrm{DO}, \mathrm{BOD}, \mathrm{NO}_{3}$, have been done and with the exception of nitrate, for other parameters, the Simulation in July was better than January. 


\section{REFERENCES}

Arrudacamargo, R; Caljuri, M.L; Fonseca Santiago, A (2010). Water Quality Prediction Using the QUAL2Kw Model in a Small Karstic Watershed in Brazil. Acta Limnologica Brasiliensia. 22(4): 486498.

Asheghmala, M.; Mohammadifazel, A.; Hamami, M (2014). Assimilative Capacity of the River in Limit Wastewater Quality Parameters. Journal of Environmental Science and Engineering. 4: 37-49. (In Persian)

Azimi, M.; Ghavasieh, A.R.; Hashemi, H.; Barkatin, S.; Jafarieghol, F (2010). Using the Qualitative Simulation Results for Evaluation of SelfPurification of Rivers Case Study: Sefidrood River. In: Proceedings of National Conference for Clean Water Approach. Tehran, Iran. September (2001). (In Persian)

Cristea, N.C.; Burgess, S.J (2010). An Assessment of the Current and Future Thermal Regimes of Three Streams Located in the Wenatchee River Basin, Washington State: Some Implications for Regional River Basin Systems. Climatic Change. 102; 493 520.

Erfanmanesh, M. Afioni, M (2006). Environmental Pollution of Water, Soil and Air. Arkan Publications. 4th Edition, 67pp. (in Persian)

Hoseini, Y.; Hoseini, A.; Moazed, H.; Mirbehresi, H.R (2007). Calculate Assimilative Capacity of the Karkheh River in Order to Determining of Municipal Wastewater Entering and comparing it with the Present Situation. In: Proceedings of First Conference of Environmental Health Engineering. Tehran, Iran. 3-4 November 2007 (In Persian)

Kannel, P.R.; Kannel, S.R.; Lee, S.; Lee, Y.S.; Thian, Y.G (2011). A Review of Public Domain Water Quality Models for Simulating Dissolved Oxygen in
Rivers and Streams, Environmental Modeling and Assessment. 16:183-204.

Mehrdadi, N.; Ghobadi, M.; Nasrabadi, T (2006). Evaluation of the Quality and Self-Purification Potential of Tajan River Using Qual2e Model, Environmental Health Science and Engineering. 3:199-204.

Mirzaee, M.; Aminirad, H.; Gholbabaiekutnaie, F.; Yusefiekebriaie, D (2012). Check the Quality of Water in Babolrood River Basin with Qual2k Software. In: Proceedings of 6th National Conference and Exhibition of Environmental Engineering. Tehran, Iran. 3-7 September 2012. (In Persian)

Mohammadi, B.; Zainolabdini, N.; Fataie, A.; Naderi, V (2015). Water Quality of Gharehsou River, in View of Assimilative Capacity. In: Proceedings of Iran's First National Conference on Science and Environmental Management. Ardabil province, Iran. 6-7 October 2015(In Persian)

Nowshadi, M.; Hatamizadeh, M (2010). Simulation and Measuring of Kur River Water Quality Using QUAL2K Model. Journal of Irrigation and Drainage. 3(4): 238-249. (In Persian)

Oliveir, B.; Bola, J.; Nadais, H.; Arroja, L (2011). Application of Qual2Kw Model as a Tool for Water Quality Management, Certima River as a Case Study, Environ Monit Assess., 184(10): 6197-210.

Pelletire, G.J.; Chapra, S.C (2005). Qual2kw-Theory and Documentation (Version 5.1) A Modeling Framework for Simulating River and Stream Quality. Washington Department of EcologyWashington State.

Selong, J.H.; Helfrich, L.A (2002). Impact of Trout Culture Effluent on Water Quality and Biotic Communities in Virginia Headwater Streams. The progressive Fish Culturist. 76: 247-262. 